\title{
Insulation Life Assement of High Voltage Transformer: A
} Review

Naveed Ahmad Dar

Lovely Professional University, Phagwara, Jalandhar

\section{Kullraj Kaur}

Lovely Professional University

Phagwara, Jalandhar, India

\section{Abstract}

The life of the transformer depends upon the insulation of the transformer. It deteriorates with due course of time in operation. It happens because of the faults in the transformer. Several techniques are used to predict the fault to diagnose it, in order to increase the life of the transformer. various artificial techniques are also used for this purpose. This paper gives the review of life assessment of insulation of transformer and various techniques are discussed.

Keywords- Transformer fault , Dissolved gas analysis, various artificial techniques.

\section{INTRODUCTION}

Transformer has an important role to play in the power system where it may be used to level up the voltage for transmission distributing the energy to consumers. So it has to live long and operate stably. The main problem in the degradation of life of transformer is the degradation of insulation in the transformer. It happens in the transformer because of several factor, some of them are included in electrical stresses and thermal stresses. These are voltage level, harmonics, use of power electronic devices, evolution of gasses, heating, water content etc. the insulation used for the transformer may be inorganic and organic, dry or oil insulation, or solids insulation which include concrete blocks, spacers etc. life of the transformer depends upon the condition of insulating material [1]. Dry insulation is mainly used in windings. Reliability of insulating system of dry insulation transformers is obtained based on three models which are degradation, regression and expert judgement. The various insulating materials used in the transformer are [2]:

Insulating fluid: mineral oil, synthetic or vegetable oil.

Conductor insulation: Kraft and Kraft paper, Nomex, Enamel

Solid insulation: barriers, blocks, spacers

The introduction of power semiconductor devices in a power system also leads to insulation degradation due to high frequency hence reduces life [2]. Distorted voltage is also responsible for insulation descent [3]. In oil immersed transformers ratio method recommended by IEC /IEEE is widely accepted also some artificial intelligence techniques have been introduced in calculating the dissolved gas analysis to overcome the short coming of ratio method [4]. For the evolution of gasses in the transformers there are three main causes which are which are included in the thermal stress. These are overheating, corona and arching. the gasses which are produced in transformer during faults are Hydrogen $\left(\mathrm{H}_{2}\right)$, Carbon monoxide $(\mathrm{CO})$, Methane $\left(\mathrm{CH}_{4}\right)$, Acetylene $\left(\mathrm{C}_{2} \mathrm{H}_{4}\right)$, Ethane $\left(\mathrm{C}_{2} \mathrm{H}_{6}\right)$, Ethylene $\left(\mathrm{C}_{2} \mathrm{H}_{2}\right)$ [5]. Transformer is the most expensive equipment in the power system hence it has to be protected from faults. Power transformers are greatly influenced by condition of insulating material. The processes like degree of polymerization, dissolved gas analysis, furan analysis are wide used to determine aging processes. Artificial techniques are used for DGA to analyze the ratio of gasses to give fault type [6]. The transformer is only monitored through DGA, water content, temperature and partial discharge detection, diagnostic winding deformation, local deformation and turn to turn faults [15]. 
Faults in transformers can be classified into two categories one is internal and another is external faults [10]. Internal faults are those which happen within the protection zone of transformers. Internal faults can be further classified as internal short circuit faults and inter incipient faults. Internal short circuit fault constitutes turn to turn or turn to earth short circuit. Incipient fault usually develops slowly in the form of deterioration of insulation. Faults can be also classified as thermal and electrical faults. Thermal is related to oil and paper which results in the production of gasses $\mathrm{C}_{2} \mathrm{H}_{4}$ and $\mathrm{C}_{2} \mathrm{H}_{6}$ from oil $\mathrm{CO}$ and $\mathrm{CO}_{2}$ from paper. Electrical faults are related to partial discharge $\left(\mathrm{H}_{2}, \mathrm{C}_{2} \mathrm{H}_{4}\right)$ and arching $\left(\mathrm{H}_{2}, \mathrm{C}_{2} \mathrm{H}_{4}\right)$ [7]. With the increase in load demand the temperature of the transformer increases which results in the decrease in insulation life. To avoid this utility resort to load shedding during high demand [14].

\section{TECHNIQUES USED}

\section{A. Dissolved Gas Annalysis (DGA)}

Different gasses are evolved from different faults, some of them are partially dissolved and some totally [8]. It has been widely accepted as it gives us the relation between gaseous concentration and type of fault. 'Halstead' proved the relationship between fault temperature and the composition of dissolved gasses. From Halstead's discovery which suggests the theoretical assessment of the formation of simple decomposition of Hydro-Carbon gases. It proves the relationship between fault, temperature and gas evolved. There are two methods used for DGA.

1. Key Gas Method: it gives us a relationship between the particular gas and the fault type [5] [15] [7] [10]

\begin{tabular}{|l|l|l|}
\hline S.NO & $\begin{array}{l}\text { GAS } \\
\text { EVOLVED }\end{array}$ & FAULT \\
\hline 1 & $\mathrm{H}_{2}$ & Corona \\
\hline 2 & $\mathrm{O}_{2} \& \mathrm{~N}_{2}$ & Non fault related gases \\
\hline 3 & $\mathrm{CO}, \mathrm{CO}_{2}$ & Cellulose insulation breakdown \\
\hline 4 & $\mathrm{CH}_{4}, \mathrm{C}_{2} \mathrm{H}_{6}$ & Low temperature oil breakdown \\
\hline 5 & $\mathrm{C}_{2} \mathrm{H}_{4}$ & High temperature oil breakdown \\
\hline 6 & $\mathrm{C}_{2} \mathrm{H}_{2}$ & Arching \\
\hline
\end{tabular}

2. Ratio Methods: These methods are used when there exists more than one fault at a time. Ratio between the gases gives us the exact fault type. Rogers Domenberg and IEC are used for ratio methods. To take the exact relation between fault type and gases evolved computer aided techniques like fuzzy logics, ANN, etc. are used to evaluate.

\section{B. Artificial Neural Network(ANN)}

Complex systems can be solved with little knowledge using artificial neural network. It can be used for calculating the relationship between gas evolved and fault in the oil immersed transformer hidden relationships are detected by the ANN and are used to develop interpretation of dissolved gas in oil. Theoretically a neural network can represent any observable phenomenon [5]. Algorithm includes selection of input and output networks. The features have to be chosen carefully so that it can reflect the characteristics of the problem [5]. It starts with training samples and these training samples are obtained experimentally through repeated experiments. The training samples are passed repeatedly through the network until we don't get the optimum solution. The algorithm for ANN is as under [5] 


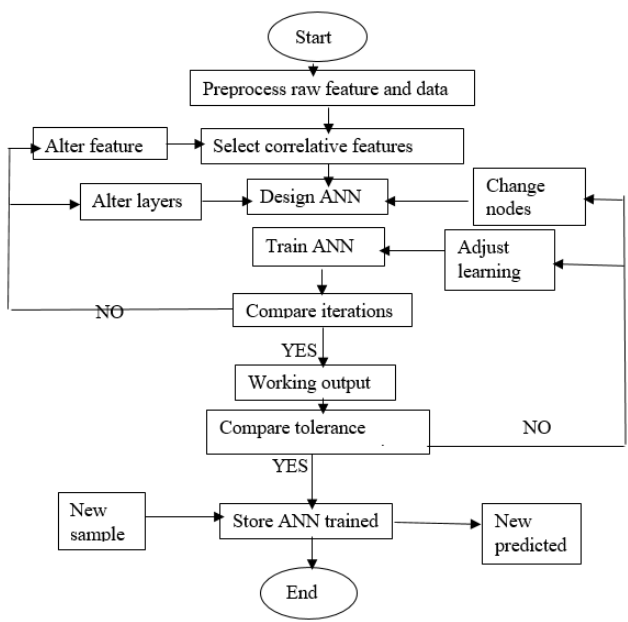

Nero imperialistic competitive algorithm (ICA) is also the form of ANN and was introduced in [15]. It is composed of many neurons which are interconnected to each other through loads. Neural networks are different from each other as per connected neuron. In neural ICA multi-layer perceptron (MLP) are utilized. All the neurons of different layers are interconnected to each other configuration as shown below [15].

\section{Block diagram for ANN}

ANN is used for nonlinear system identification. Work has also been done using adaptive learning algorithm of power transformers for fault diagnosis [6]

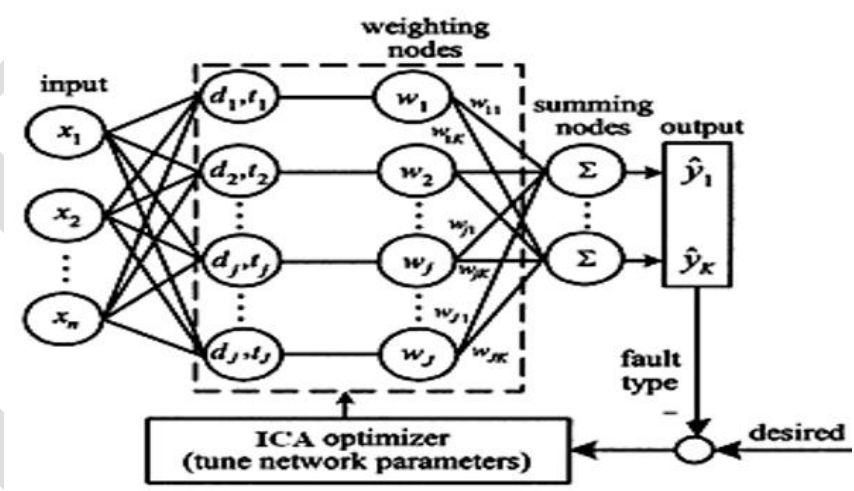

\section{Fuzzy Logic}

Fuzzy logic consists of three processes, namely, fuzzification, fuzzy inference, Defuzzification. The gases evolved during faults are taken in ratios like $\mathrm{CH}_{4} / \mathrm{H}_{2}, \mathrm{C}_{2} \mathrm{H}_{4} / \mathrm{CH}_{4}, \mathrm{C}_{2} \mathrm{H}_{4} / \mathrm{C}_{2} \mathrm{H}_{6}$ and $\mathrm{C}_{2} \mathrm{H}$. ${ }_{2} / \mathrm{C}_{2} \mathrm{H}_{4}$ are then converted into codes according to its causing fault, which are overheating, corona, and arching [6]. The explicit Data is given as an input for fuzzification then it converts it into fuzzy membership function. Fuzzy inference processes the membership function into defined fuzzy rule set and results into fuzzy output statement. Defuzzifier converts the fuzzy statement into output crisp data. Configuration is given in [17].

\section{Configuration of fuzzy logics}

Fuzzy asset management design mode was introduced by Norazhar Abu Bakar, A. Abu Sadia [9]. Some constraints were examined for proper maintenance of transformer these are aging criticality, contamination criticality and relative accelerating aging [9]. 


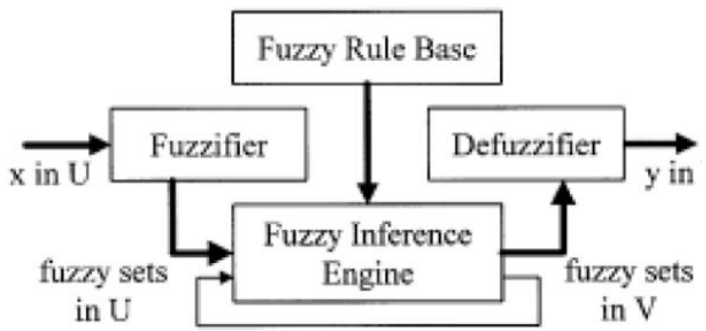

\section{Expert system diagnosis}

The objective of monitoring equipment is to prevent shutdown and unnecessary maintenance. Expert system helps us to avoid in correct diagnosis. Christina Ciulava, Elena Helera, proposed an IF-THEN expert diagnosis [10] procedure for online monitoring. In this procedure various IFTHEN statements are used to connect various sensor measurements. Expert system is a software that uses artificial techniques to achieve the performance of human experts. It can be also used with the Neural Fuzzy technique known as Neuro Fuzzy Expert System [6]. These techniques are used together for comparing the results for the optimum diagnosis of the system. The block diagram of Expert diagnosis is [16]

\section{E. Degree of polymerization}

\section{Block diagram for expert diagnosis system}

Degree of polymerization is the average number of monomer molecules forming the polymer the monomer molecule in case of paper insulation is glucose $\left(\mathrm{C}_{6} \mathrm{H}_{10} \mathrm{O}_{5}\right)$ [11]. Degree of polymerization is a technique to access the condition of insulating paper it gives us the relationship tween degradation of insulation and aging products as we know paper craft is actually a cellulose molecule after decomposition of cellulose it forms a monomer glucose molecule, which in turn forms a big macro molecule [12]. The chemical reaction degrades the paper and its degree of polymerization falls. Aging is actually a process of de-polymerization which are bought out through hydrolysis, pyrolysis and oxidation [13]. the rate of aging process is given by [18] [11]

$$
K_{t}=\frac{1}{D P_{t}}-\frac{1}{D P_{0}}
$$

$\mathrm{K}_{\mathrm{t}}$ is the rate of reaction, $\mathrm{DP}_{\mathrm{t}}$ is a degree of polymerization at time $(\mathrm{t}=\mathrm{t})$ and $\mathrm{DP}_{0}$ is the degree of polymerization at time $(\mathrm{t}=0)$

Water reacts with paper through atmosphere indirectly. Firstly, atmospheric oxygen reacts with oil forming hydro peroxides which further reacts and forms carboxylic acids as acids are rich in protons it reacts with water and transfers the proton which afterword reacts with cellulose and forms monomer molecule. Hence water is important in paper degradation rate control. Temperature enhances the chemical reaction, with the increase in temperature the degradation increases.

The equation for degree of polymerization is given by [19]

$$
D P(\mathrm{t})=\frac{D P\left(\mathrm{t}_{0}\right)}{1+D P\left(\mathrm{t}_{0}\right) \int_{\mathrm{t} 0}^{t} K(\tau) \mathrm{d} \tau}
$$

$\mathrm{DP}(\mathrm{t})$ is the degree of polymerization at time $(\mathrm{t}=\mathrm{t}), \mathrm{k}(\tau)$ is the rate of reaction and $\mathrm{DP}\left(\mathrm{t}_{0}\right)$ is the degree of polymerization at time $(\mathrm{t}=0)$. It has been obtained from Arrhenius equation [1]

$$
k(t)=A e^{\frac{-E}{R T(t)}}
$$




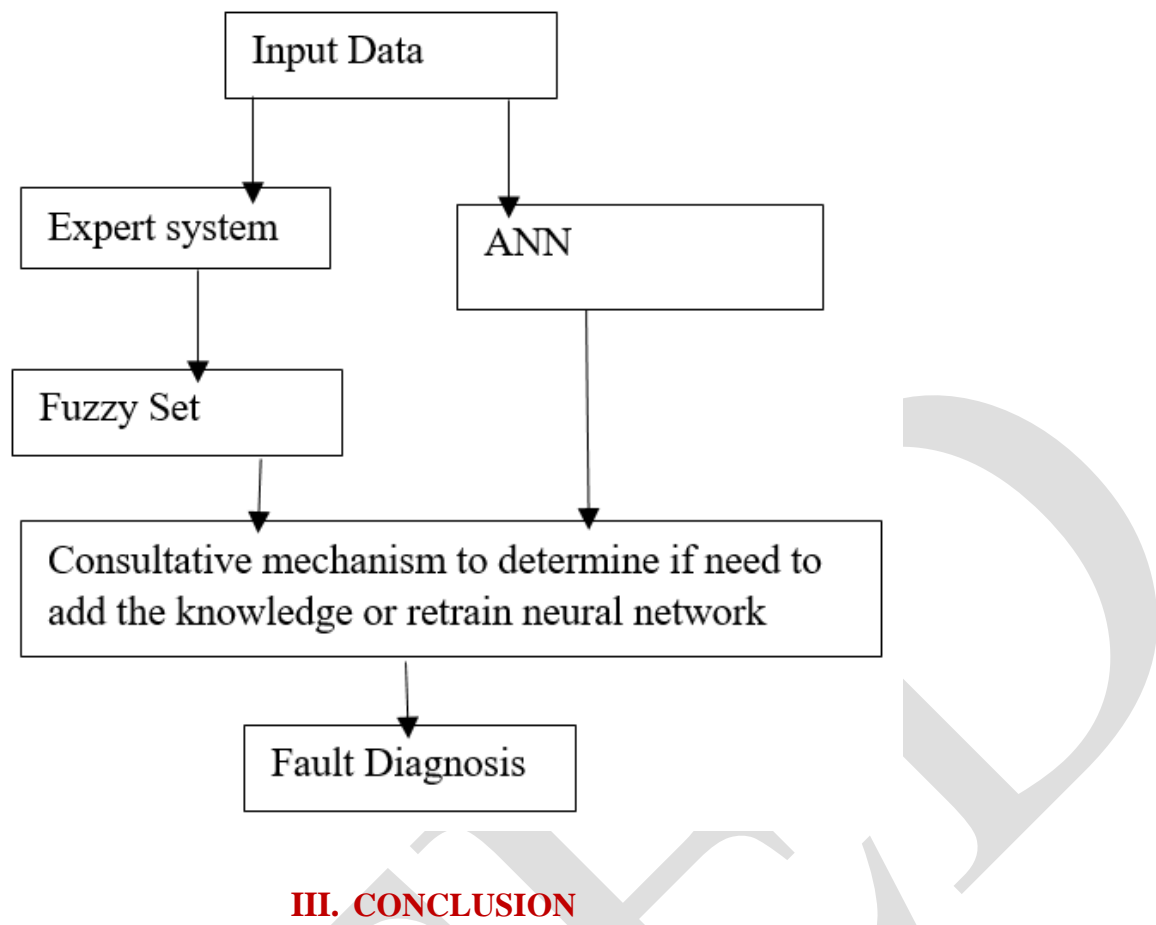

In this paper we presented the review of life assessment of insulation of high voltage transformer. Different techniques have been discussed which can help in predicting the life of a transformer. There are various factors which can affect the life of an insulation of the transformer. With proper monitoring and maintenance, we can increase the life of the transformer. Monitoring can be done by various methods and then the result can be used in various techniques like Dissolved Gas Analysis, Partial Discharge, Degree of Polymerization etc. then the accurate life assessment and maintenance can be done. These techniques can be combined with artificial Algorithm techniques to have precise results by which timely maintenance can be achieved along with exact location of fault and type of the fault occurred. These techniques have disadvantages in parallel with advantages, depending upon the conditions, reliable and matching techniques is used.

\section{REFERENCES}

[1] Minmin Wen; Jiancheng Song; Yuan Song; Yuan Liu; Chuanyang Li; Peng Wang "Reliability assessment of insulation system for dry type transformers" .IEEE Transactions on Dielectrics and Electrical Insulation Year: 2013, Volume: 20, Issue: 6 Pages: 1998 - 2008

[2] W. Ziomek; K. Vijayan; D. Boyd; K. Kuby; M. Franchek "High voltage power transformer insulation design "2011 Electrical Insulation Conference (EIC). Year: 2011 Pages: 211 - 215

[3] M. Nagel; T. Leibfried "Investigation on the high frequency, high voltage insulation properties of mineral transformer-oil" 2006 IEEE Conference on Electrical Insulation and Dielectric Phenomena Year: 2006 Pages: 226 - 228

[4] M. Dong; D. K. Xu; M. H. Li; Z. Yan "Fault diagnosis model for power transformer based on statistical learning theory and dissolved gas analysis "Conference Record of the 2004 IEEE International Symposium on Electrical Insulation Year: 2004 Pages: 85 - 88

[5] Y. Zhang; X. Ding; Y. Liu; P. J. Griffin” An Artificial Neural Network Approach to Transformer Fault Diagnosis" IEEE Power Engineering Review Year: 1996, Volume: 17, Issue: 13 Pages: 55 - 55

[6] Amritpal Singh; P. Verma "A review of intelligent diagnostic methods for condition assessment of insulation system in power transformers" 2008 International Conference on Condition Monitoring and Diagnosis Year: 2008 Pages: 1354 - 1357 
[7] A. Abu-Siada; S. Islam" A new approach to identify power transformer criticality and asset management decision based on dissolved gas-in-oil analysis" IEEE Transactions on Dielectrics and Electrical Insulation Year: 2012, Volume: 19, Issue: 3 Pages: 1007 - 1012

[8] Diego M. Robalino; Satish M. Mahajan” Dissolved gas analysis of a thermally overloaded oilimmersed current transformer" 2010 IEEE/PES Transmission and Distribution Conference and Exposition: Latin America (T\&D-LA) Year: 2010 Pages: 645 - 652

[9] Norazhar Abu Bakar; A. Abu-Siada" Fuzzy logic approach for transformer remnant life prediction and asset management decision"'IEEE Transactions on Dielectrics and Electrical Insulation Year: 2016,Volume: 23, Issue: 5 Pages: 3199 - 3208

[10] Ciulavu, Cristina \& Helerea, Elena. (2008). "Power transformer incipient faults monitoring" Ann Univ Craiova-Electr Eng ser. 32..

[11] D. Martin; T. Saha; O. Krause; G. Buckley; S. Chinnarajan; R. Dee; G. Russell "Improving the determination of water content of power transformer insulation paper near the end of its functional life" 2016 Australasian Universities Power Engineering Conference (AUPEC) Year: 2016 Pages: $1-6$

[12] Abu Bakar Norazhar; A. Abu-Siada; S. Islam "A review on chemical diagnosis techniques for transformer paper insulation degradation"2013 Australasian Universities Power Engineering Conference (AUPEC) Year: 2013 Pages: $1-6$

[13] L. E. Lundgaard; W. Hansen; D. Linhjell; T. J. Painter" Aging of oil-impregnated paper in power transformers" IEEE Transactions on Power Delivery Year: 2004, Volume: 19, Issue: 1 Pages: $230-239$

[14] Charan Teja S; Pradeep Kumar Yemula" Reduction in loss of life of transformer with demand response” 2016 IEEE Region 10 Conference (TENCON) Year: 2016 Pages: 2679 - 2683.

[15] Mehrdad Beykverdi, F. Faghihi, A. Moarefian pour" A New Approach for Transformer Incipient Fault Diagnosis Based on Dissolved Gas Analysis (DGA)" Nova Journal of Engineering and Applied Sciences Vol 2(3), March 2014: 1-8

[16] Ding H,"An expert system for large power transformer fault diagnosis expert system applicationto power system 'IV proceeding UK Page 499-502(1992).

[17] Chen AN-Pin, Chang-Chun"Fuzzy approaches for fault diagnosis of transformers"2001

[18] A. M. Emsley, X. Xiao, R. J. Heywood, \& M. Ali, "Degradation of cellulosic insulation in power transformers. Part 3: Effects of oxygen and water on ageing in oil", Proc. IEE Sci., Measur. Techn., Vol. 147, pp. 115-119, 2000

[19] A Van Schijindel"Power transformer reliability disertation "Department of Electrical Engineering, Eindhoven University of Technology Eindhoven Nitherland 2010. 